\title{
BMJ Open Patients' perceptions of continuity of care across primary care level and emergency departments in Belgium: cross-sectional survey
}

\author{
Marlene Karam (1D , Anne-Sophie Lambert, Jean Macq
}

To cite: Karam M, Lambert A-S, Macq J. Patients' perceptions of continuity of care across primary care level and emergency departments in Belgium: crosssectional survey. BMJ Open 2019;9:e033188. doi:10.1136/ bmjopen-2019-033188

- Prepublication history and additional material for this paper are available online. To view these files, please visit the journal online (http://dx.doi. org/10.1136/bmjopen-2019033188).

Received 24 July 2019 Revised 22 0ctober 2019 Accepted 11 November 2019

Check for updates

(C) Author(s) (or their employer(s)) 2019. Re-use permitted under CC BY-NC. No commercial re-use. See rights and permissions. Published by BMJ.

Faculty of Public Health, Institute of Health and Society, Catholic University of Louvain Health Sciences Sector, Brussels, Belgium

Correspondence to Dr Marlene Karam; marlene.karam@uclouvain.be

\section{ABSTRACT}

Objectives To assess patients' perceptions of continuity of care (COC) across primary care level and emergency departments (EDs) and to identify contextual and individual factors that influence this perception.

Design Cross-sectional multicentre survey.

Setting Five EDs in Brussels and Wallonia.

Participants 501 adult patients referred to the ED by their primary care physician (PCP). Patients with cognitive impairment or in critical condition were excluded.

Results Patients perceived high levels of the three types of COC. On an individual level, older patients showed a perception of higher levels of continuity. Lower levels of informational and management continuity were observed among patients suffering from chronic diseases and patients with a high level of education. Patients also perceived a redundancy of medical exams, in parallel to a high degree of accessibility between care levels. On an organisational level, three structural factors were identified as barriers to COC, namely, ED workload, suboptimal sharing information system and the current fee-for-service payment system that encourages competition and hinders coordination between actors

Conclusion Belgian healthcare services seem satisfying for patients and easily accessible. However, efforts need to be directed towards improving their efficiency. A stronger primary care level is also needed to benefit the healthcare system by reducing overuse of emergency services. On the individual level, a more enhanced patient-centred approach could be beneficial in improving patients experience of care.

\section{BACKGROUND}

Consistent, timely communication of health record information between emergency departments (EDs) and primary care level is a necessity for the provision of high-quality patient care. ${ }^{1}$ Indeed, communication issues between the two levels of care have been identified as an important contributor to the breakdown in continuity of care (COC) ${ }^{2}$ and have resulted in delays and omissions in follow-up care for patients. ${ }^{3}$

In Belgium, the limitations of communication tools between EDs and primary care level

\section{Strengths and limitations of this study}

- This is the first study to assess the three types of continuity of care $(\mathrm{COC})$ across emergency departments (EDs) and primary care level.

- Experience of continuity in healthcare is viewed from the patient's perspective.

- The multicentre design allows having heterogeneous contexts which strengthen the generalisability (external validity) of the investigation to Brussels and Wallonia regions.

- Patients who were not referred to ED by their primary care physician were excluded, which may have left out important data on their perception of COC.

- Flemish-speaking regions of Belgium were not included, which limits the generalisability of the results to a national level.

have led to $75.7 \%$ of primary care physicians (PCPs) and $85.7 \%$ of emergency physicians in Wallonia to be dissatisfied with communication between their two levels of care. ${ }^{4}$ Referral letters written by PCPs are of variable quality and occasionally lack essential information ${ }^{4}$; EDs' written reports are sometimes sent to PCPs only months later, with some reports even sent to inaccurate addresses. ${ }^{5}$ Furthermore, shared patient records are underused, mainly because many physicians are untrained in using these systems or because of the additional administrative tasks required for enrolling patients and keeping their data updated on the platform. ${ }^{5}$ These factors raise a significant challenge in terms of informational continuity for patients between the emergency physician and their PCP. Informational continuity refers to 'how well a patient's health information is able to "travel" with him/her throughout the health services system, including over time, with the same practitioner and between practitioners in different settings'. ${ }^{6}$ In addition to informational continuity, two other types of continuity 
have been described in the literature. First, relational or interpersonal continuity appears in 'the ongoing relationship between the patient and her/his family and the care provider ${ }^{6}{ }^{6}$ Second, management continuity ensures that care received from different providers is connected in a coherent way. ${ }^{7}$ These three types of continuity should be examined simultaneously since they are shown to be inter-related. ${ }^{8}$ Timely electronic communication of ED records to PCPs has the potential to reduce unnecessary duplication of tests and referrals, reduce gaps in COC, improve patient and family perceptions of COC, enhance 'circle of care' relationships between hospital-based and community physicians, ${ }^{1}$ and prevent patient feelings of loneliness when receiving different opinions. ${ }^{8}$

Several reports support the idea that experiences of continuity in healthcare must be viewed from the patient's perspective, where the patient can provide a global picture of his care experiences along the continuum of care. ${ }^{8}$ Moreover, the value of COC differs for various patients at different times and for different problems. ${ }^{10}$ It is relevant therefore to assess the achievement of continuity from the patient's perspective. To our knowledge, COC across primary care and EDs from the perspective of users has not been studied.
The aim of this study was to assess patients' perceptions of COC across primary care and EDs in Brussels and Wallonia. We also aimed to identify individual and contextual factors that influence this perception.

\section{METHODS}

\section{Design and setting}

A cross-sectional study was conducted in five EDs in Brussels and Wallonia. We aimed to diversify the context, thus selecting EDs from regions with different socioeconomic characteristics. Participating EDs also had organisational differences between them. These characteristics are reported in table 1 .

\section{Survey instrument}

The continuity of care across levels of care (CCAENA) is a useful instrument that measures patient-experienced COC as a multidimensional concept, regardless of morbidity and across multiple care settings. ${ }^{11}$ With the authors' permission, we adapted this questionnaire, initially designed to assess the PCP-specialist interaction, using a Delphi expert consensus method. ${ }^{12}$ We started by following the translation and back-translation

Table 1 Organisational and socioeconomic characteristics of the participating EDs, by region

\section{Organisational characteristics of the hospital EDs}

\begin{tabular}{|c|c|c|c|c|c|}
\hline & Region & Setting & Socioeconomic characteristics ${ }^{5}$ & General characteristics & Communication tools with PCPs \\
\hline ED 1 & Dinant & Rural & $\begin{array}{l}\text { The socioeconomic indicators } \\
\text { (average income, unemployment } \\
\text { and social integration income) } \\
\text { are less positive compared with } \\
\text { Wallonia. }\end{array}$ & $\begin{array}{l}\text { University, private } \\
\text { hospital. } \\
15556 \text { admissions/ } \\
\text { year. }\end{array}$ & $\begin{array}{l}\text { Combination of written reports, } \\
\text { shared medical records and phone } \\
\text { calls }\end{array}$ \\
\hline ED 2 & Ottignies & urban & $\begin{array}{l}\text { Good socioeconomic status in } \\
\text { general and a higher average } \\
\text { income in comparison with } \\
\text { Wallonia (+23.3\%), high population } \\
\text { growth since } 1990(+23.2 \%) \text { with } \\
\text { increased educational level. }\end{array}$ & $\begin{array}{l}\text { General, public } \\
\text { hospital. } \\
\text { Presence of PCPs } \\
\text { within the ED } \\
\text { physicians' team. } \\
\text { 49 } 763 \text { admissions/ } \\
\text { year. }\end{array}$ & Written reports and phone calls \\
\hline ED 3 & Charleroi & Urban & $\begin{array}{l}\text { Low socioeconomic status, } \\
\text { lower incomes compared with } \\
\text { the Belgian population, more } \\
\text { unemployment, more single-parent } \\
\text { families, fewer tertiary graduates. }\end{array}$ & $\begin{array}{l}\text { General, private } \\
\text { hospital. } \\
31214 \text { admissions/ } \\
\text { year. }\end{array}$ & $\begin{array}{l}\text { Combination of written reports, } \\
\text { emails, shared medical record and } \\
\text { phone calls }\end{array}$ \\
\hline ED 4 & Brussels & Urban & $\begin{array}{l}\text { Diversity in origin, cultural } \\
\text { background and socioeconomic } \\
\text { status; about one-third of the } \\
\text { population is living with an income }\end{array}$ & $\begin{array}{l}\text { General, private } \\
\text { hospital. } \\
43142 \text { admissions/ } \\
\text { year. }\end{array}$ & $\begin{array}{l}\text { Shared medical record and phone } \\
\text { calls }\end{array}$ \\
\hline ED 5 & & & below the risk threshold of poverty. & $\begin{array}{l}\text { University, public } \\
\text { hospital. } \\
\text { Presence of PCPs } \\
\text { within the ED } \\
\text { physicians' team. } \\
\\
52919 \text { admissions/ } \\
\text { year. }\end{array}$ & Written reports and phone calls. \\
\hline
\end{tabular}

ED, emergency department; PCP, primary care physician. 
procedure. Second, we replaced 'specialist' by 'emergency physician' in all items and invited 12 experts (7 PCPs and 5 emergency physicians) to review the modified items independently to assess content validity. This is defined as 'expert judgments about the instrument's content to confirm the relevance and representativeness of the items covering the domains of the concept that is being measured'. ${ }^{13}$ Experts were selected based on their clinical expertise, position and teaching activities. In the first round of this online survey, we asked them to rate the relevance of each item on a 4-point scale and to make any necessary modifications to improve the relevance or clarity of the text. In addition, we asked them to add other important items that must be included in an instrument for measuring COC between PCPs and emergency physicians. Based on the results of the first round, we developed a second questionnaire and submitted it back to the experts who, again, recorded their opinions. The process ended with the third round, where a consensus was reached; the final questionnaire consisted of 30 items covering the three types of continuity using a Likert scale (always, often, rarely and never). In this final version, only items related to accessibility between levels were fundamentally changed. Newly added items investigated the waiting time in the ED, the financial barriers to care and whether the PCP informs the ED of the patient's arrival when necessary. Twelve additional questions covered general morbidity and sociodemographic data (see online supplementary file 1). The new questionnaire was pilot tested with a random sample of 25 patients referred to the ED by their PCP. No changes to the questionnaire were made after the pilot test.

\section{Participants}

The sample size calculated to achieve enough statistical power at a 95\% confidence level was approximately 400 patients. Patients were recruited consecutively until a sample of 100 adult patients per ED, 501 patients in total, was reached. Inclusion criteria were (1) patients above 18 years old; (2) referral to the ED by their PCP through a referral letter, phone call or both (this criterion excludes patients who are not registered with a regular PCP); and (3) having oral and written French comprehension. Excluded patients were those with cognitive impairment and those in the ED critical care zone.

\section{Data collection}

Data were collected between November 2016 and April 2017. Trained research assistants personally approached eligible patients in the ED once they were cleared for discharge or hospitalisation. The assistants explained the objectives and nature of the survey and gave patients an informational letter. Those who accepted to participate completed the paper questionnaire.

\section{Data analysis}

SPSS V.25 was used to analyse the data. Since the number of cases of missing values (including the category 'I don't know') was extremely small, we decided to use a pairwise deletion approach. Descriptive statistics of individual sociodemographic variables were calculated for each hospital and for the total sample. Each item was dichotomised (always and often vs rarely and never). Two score items (management continuity: care coherence 4 and management continuity: accessibility between levels 3) were reversed.

For each item, the proportion of patients who perceived a low level of COC was presented across the different categories of sociodemographic variables and hospitals. A $\chi^{2}$ test was used for the comparison of the proportion of patients who perceived a low level of COC. When the $\chi^{2}$ was significant, a pairwise comparison between pairs of proportions using the Holm method was computed to determine which categories were significantly different.

For the total score of each type of continuity, since the continuous variables did not follow a normal distribution, the median and its interquartile space were presented. Continuous variables were compared between two groups using the Mann-Witney test and between more than two groups using the Kruskal-Wallis test. When the KruskalWallis test was significant, a pairwise comparison using the Mann-Witney test with the Holm method was computed to determine which categories were significantly different.

For aesthetics within the tables, $p$ values are presented by colour. Green indicates proportions that are significantly lower (indicating a perception of higher COC), and red indicates significantly higher proportions. Medians are also presented in the same colours. Logically, lower medians indicate a perception of lower COC.

As for the comparison between hospitals, a multilevel analysis was performed to test confounding factors (sociodemographic variables). None explained the variability between hospitals.

\section{Patient and public involvement}

Participants and the public were not involved in the development of the research questions, study or recruitment.

\section{RESULTS}

A total of 501 patients completed the questionnaire. Only 14 patients declined, which represents a response rate of $97.2 \%$. The reasons for non-participation were lack of time (11 patients) and lack of interest (3 patients). We could not collect any sociodemographic data for nonrespondents since they did not provide us with informed consent.

\section{Participant characteristics}

Sociodemographic and morbidity characteristics of all participants are presented in table 2 , as well as their distribution between EDs. The total sample is homogenous in terms of gender and morbidity. Almost $20 \%$ of patients are aged above 80 years old. The mean age was 59.5 years and the SD was 20.8. Patients with a low education level (primary and secondary levels) represent $64 \%$ of the 
Table 2 Characteristics of participants and their distribution between EDs

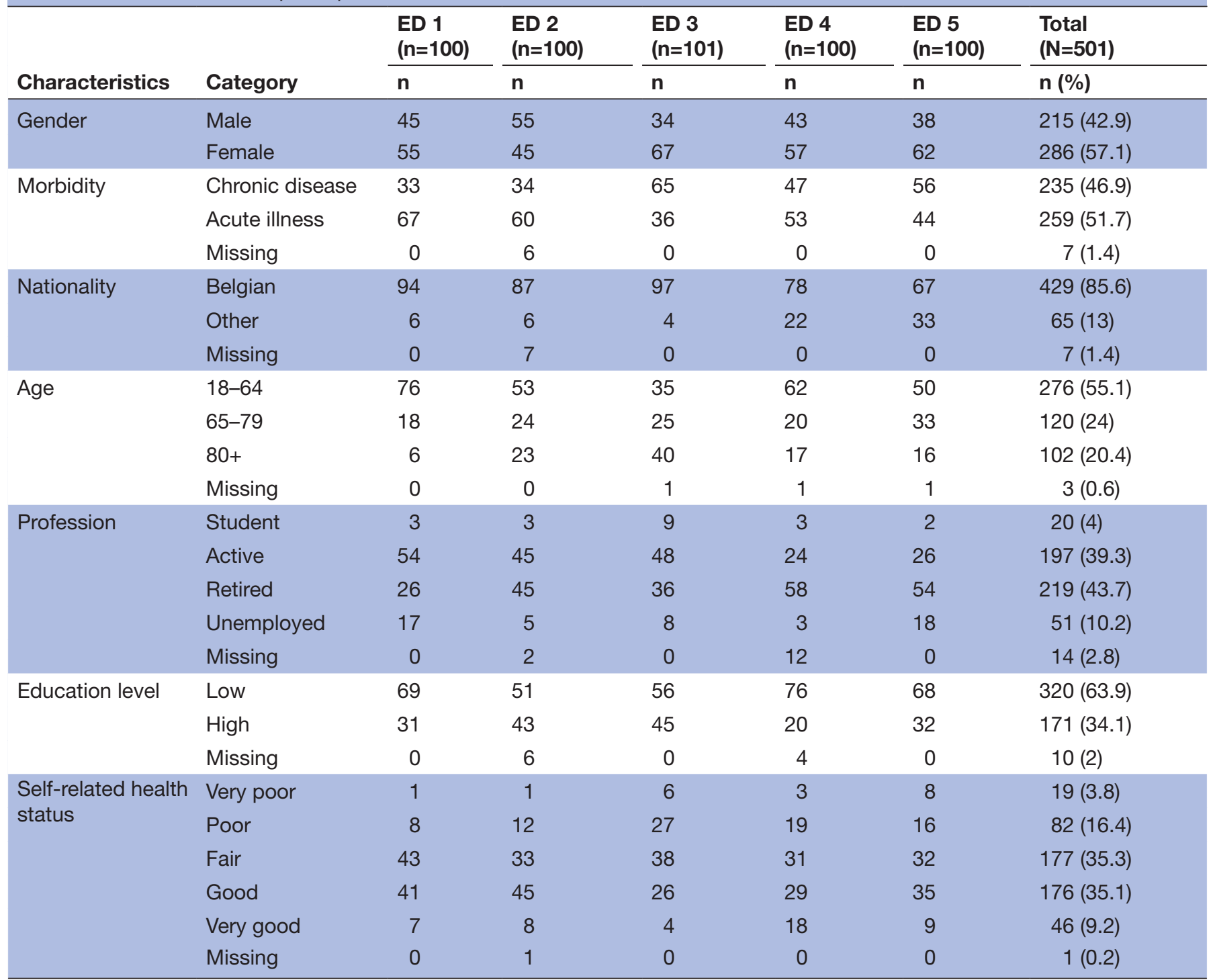

ED, emergency department.

total sample, while only $34 \%$ have a university or a nonuniversity higher education level (high level).

\section{Patients' perceptions of $\mathrm{COC}$ in relation to individual characteristics}

In general, patients perceived high levels of all types of COC. As shown in table 3 , almost $80 \%$ of patients had an overall high to very high perception of COC. However, significant differences were observed in relation to some individual characteristics, namely, morbidity, education level and age. Given the overall perceptions of high COC, we chose to present the characteristics of patients who perceived lower levels of COC. We present these results in table 4 . Results where no significant differences were observed in relation to these characteristics are presented in online supplementary file 2 .

Patients suffering from chronic diseases perceived a lower level of informational and management continuity on several items. For instance, 25\% declared their PCP does not discuss their visits to the ED with them, and $50 \%$ thought that their PCP does not inform the emergency physician of their arrival to the ED, when necessary.

Patients with a high level of education also perceived a lower level of informational and management continuity on several items. For instance, $40.5 \%$ thought that their healthcare providers do not know their medical history, and almost $15 \%$ were less likely to believe that the emergency physician agrees with the instructions of their PCP.

Younger people were also more likely to perceive a lower level of informational and management continuity. For instance, $28.6 \%$ believed their PCP is not aware of the instructions given to them by the emergency physician; also, $49.4 \%$ declared that their PCP does not inform the emergency physician of their arrival to the ED.

For these three groups, the overall perception of informational and management continuity (care coherence) scores was significantly lower. In addition, more than 
Table 3 Participants' perceptions of COC

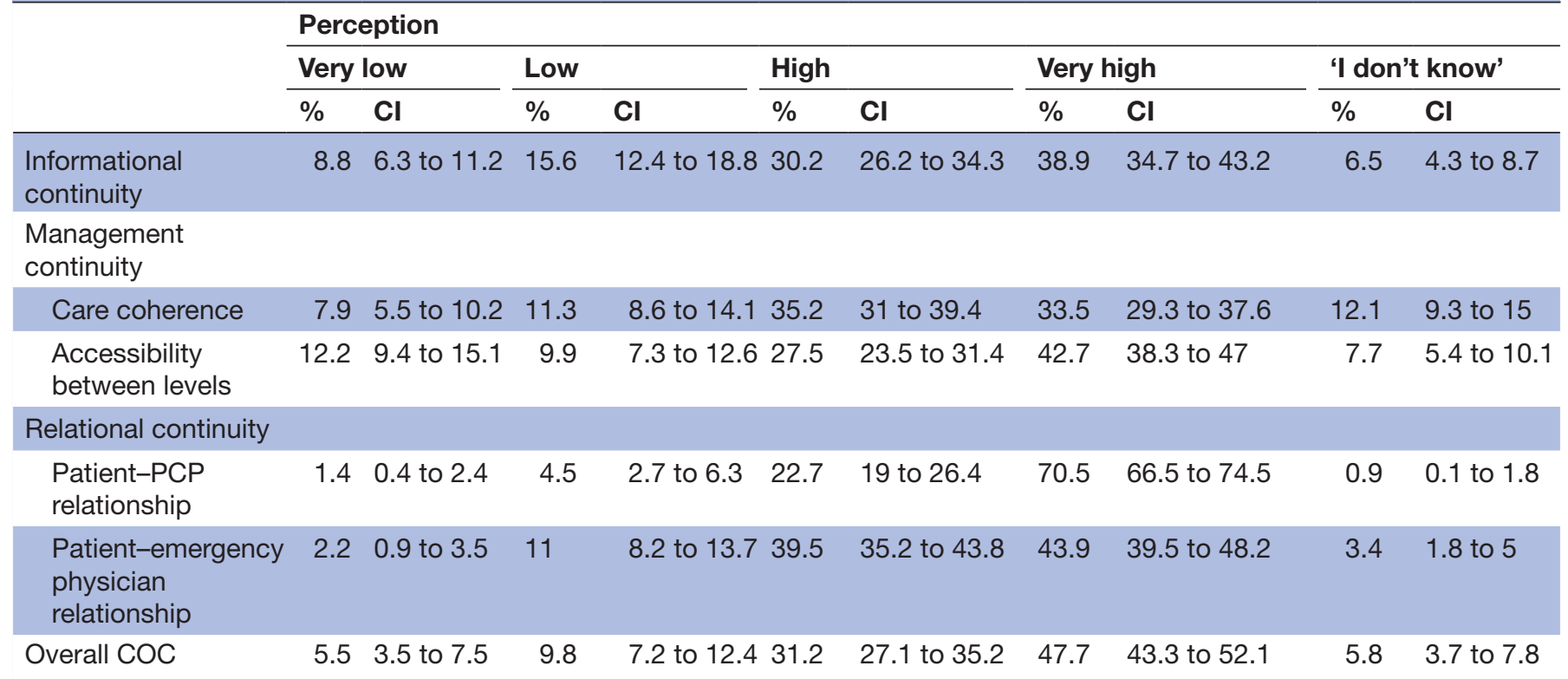

COC, continuity of care; PCP, primary care physician.

$50 \%$ of patients, regardless of individual characteristics, perceived low levels of care coherence related to redundant medical investigations.

Finally, a high degree of accessibility between levels of care was noted, with no significant differences between groups. Patients agreed that they do not have to wait a long time to be seen and cared for, at both healthcare levels (see online supplementary file 2).

No significant differences were observed in regard to sex, nationality, profession or self-related health status. Results of perceived COC regarding these characteristics are reported in online supplementary file 3 .

There was an overall perception of high levels of relational continuity with PCPs and emergency physicians, although relational continuity with emergency physicians had slightly lower scores. Results of patients' perceptions of relational continuity are presented in online supplementary file 4 .

\section{Patients' perceptions of $\mathrm{COC}$ in relation to organisational characteristics}

Significant differences were also observed in relation to organisational characteristics. We present these results in table 5. Non-significant differences are reported in online supplementary file 5 .

In general, patients from the Brussels area had a lower perception of informational and management continuity compared with other areas. For instance, patients from ED 4 and ED 5 (both in Brussels) were less likely to believe that their PCP is aware of the emergency physician's instructions, compared with $14 \%$ in the rural area. Moreover, around $50 \%$ of patients from both EDs in Brussels thought that their PCP and the emergency physician do not communicate with each other, compared with significantly lower percentages in other areas. Also, overall perception of informational and management continuity (accessibility between levels) was significantly lower in the Brussels area compared with rural areas.

In parallel, almost $77 \%$ of patients from rural areas had a significantly lower perception of care coherence related to redundant medical investigations, compared with those from the two EDs in Brussels (55.2\% and 51.5\%).

In addition, we observed significantly lower scores for ED 3 in Charleroi in terms of relational continuity with the emergency physician, where a high percentage of patients (1) did not feel comfortable discussing their doubts and health problems with the emergency physician, (2) were less likely to believe that the emergency physician cares about them and (3) were less likely to believe that the given information was sufficient.

Almost all patients perceived very high levels of relational continuity with PCPs, with no differences observed between EDs; these results are presented in online supplementary file 5 .

\section{DISCUSSION}

Our results showed an overall perception of high COC for the three types of continuity. However, when examining specific attributes of informational and management continuity, we were able to identify significant differences related to individual factors.

Patients suffering from chronic diseases perceived lower levels of informational and management continuity for certain attributes. Yet, COC becomes increasingly important for patients with comorbidities and complex problems who are under the care of several healthcare providers at various points in time. ${ }^{14-16}$ For these patients, gaps in informational continuity are common and result 


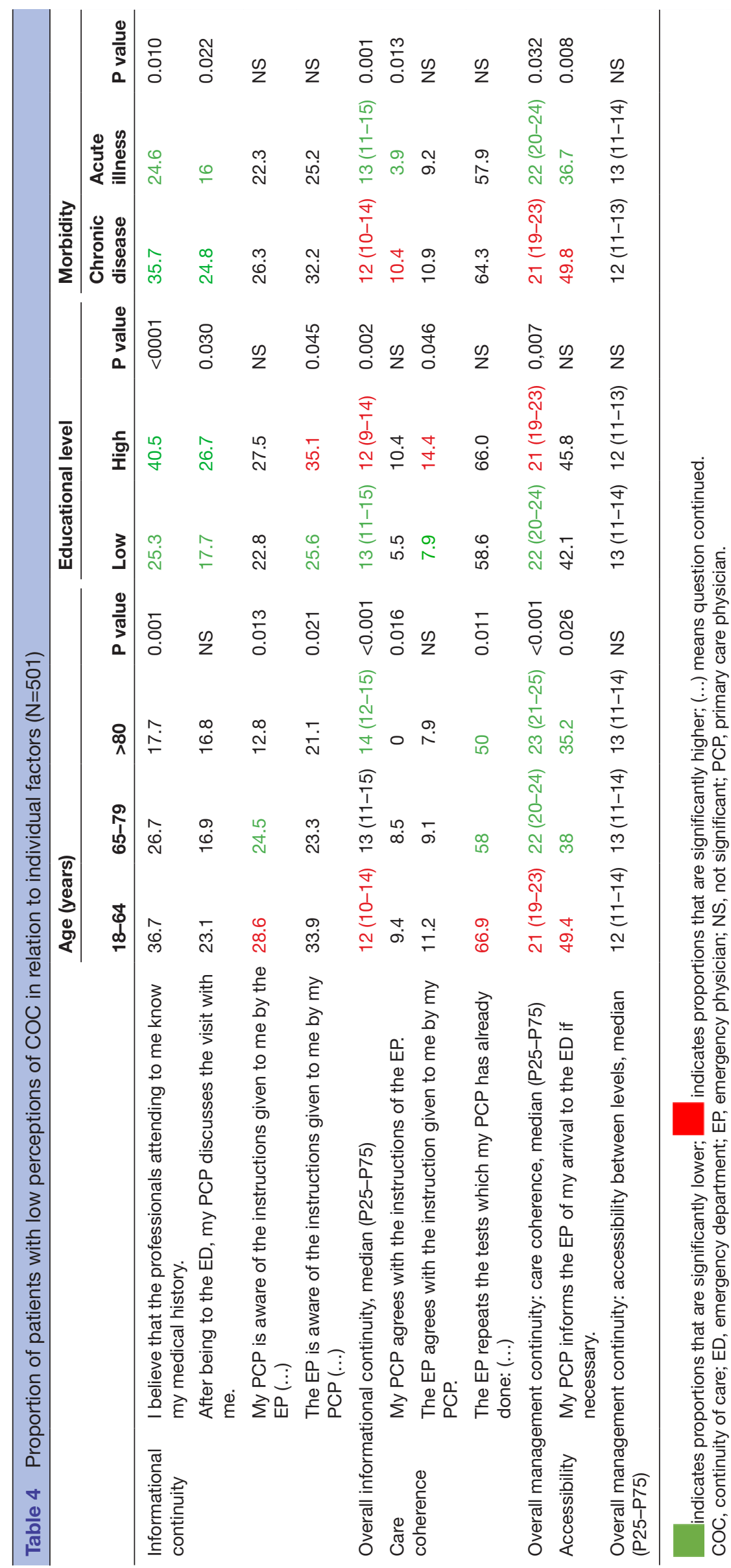

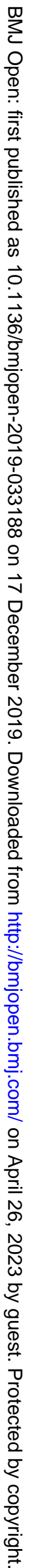




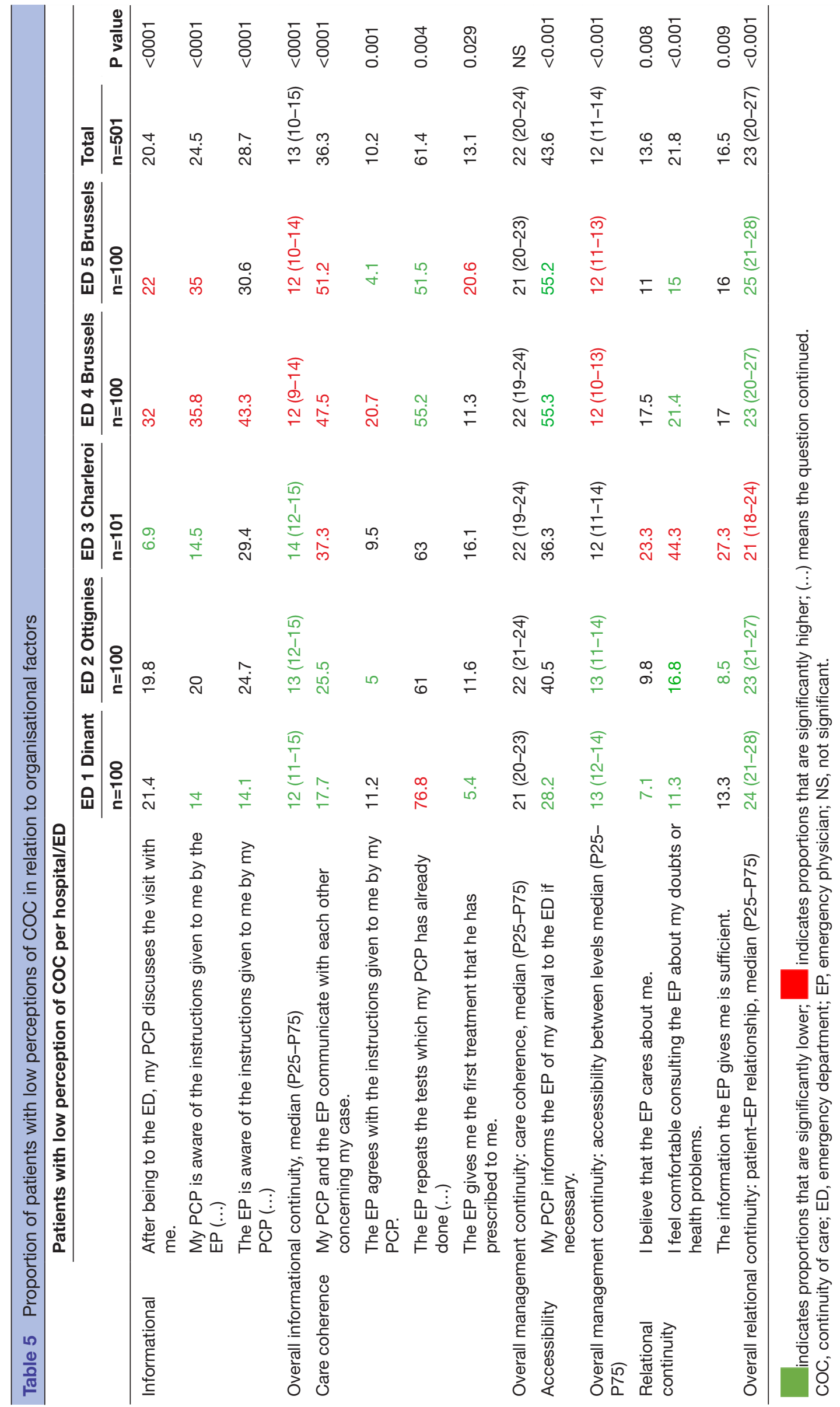


in poor management continuity. For example, informational discontinuity following hospital discharge leads to disrupted or delayed care, delays in medication prescriptions, and confusion and dissatisfaction among patients. ${ }^{17}$

Patients who are more educated are shown to have higher expectations, to judge quality more critically and to elicit more information. ${ }^{18} 19$ Our results also suggest that these patients are more likely to think that the emergency physician is not aware of the instructions given by their PCP. This is at odds with the fact that all participants were referred to the ED by their PCP. Again, this highlights the controverted quality and incompleteness of some referral letters.

Patients older than 80 years showed a perception of higher levels of informational and management continuity on almost every item. Particularly, they were more likely to believe that, if necessary, their PCP informs the emergency physician of their arrival to the ED. Indeed, PCPs prefer to use this direct approach because it allows a direct interaction and case discussion between healthcare providers ${ }^{5}$ and helps to reduce waiting time for the elderly in the ED. At the same time, older people are shown to express greater satisfaction with the care received and have more realistic expectations. ${ }^{20}$ They also have a better knowledge of the system due to more frequent use of healthcare services. ${ }^{18}$

Most patients perceived a high degree of accessibility between levels of care related to minimal waiting times to be seen and cared for in both levels. In 2015, Belgium had 139 hospitals with an ED, which is equivalent to $1.24 \mathrm{ED}$ per 100000 populations. This figure is higher than in neighbouring countries (0.33 in England, 0.39 in Denmark and 0.54 in France) and explains the high accessibility of Belgian EDs. ${ }^{21}$

The density of PCPs in Brussels is estimated at 11.7 per 10000 populations. ${ }^{22}$ In Wallonia, it is estimated at 6.92 in rural areas and varies between 8.2 and 9.9 in urban areas. ${ }^{23}$ These figures are intermediate compared with other European countries, such as France $(13.2)^{24}$ or England (7.0) ${ }^{25}$ Thus, it does not explain the perception of high accessibility to PCPs reported in our study. Rather, patients' perceptions of high levels of management continuity could be influenced by high levels of relational continuity in the form of trusted relationships with their PCP and after-hours availability.

Regarding relational continuity, all patients perceived high levels with their PCPs, which could be because our sample includes patients who are registered with a regular PCP. Indeed, seeing the same PCP each time was described as a factor for fostering trust between the patient and their PCP, accumulating mutual knowledge of each other and developing a relational COC. ${ }^{26}$

On the other hand, hospital-based systems of care traditionally give lower priority to relational continuity. In these contexts, COC becomes the result of a patient's trust in 'their' hospital or ED, the quality of teamwork observed and the degree of coordination with their PCP. ${ }^{17}$ This was probably the case for our participants who all perceived a high level of relational continuity with their emergency physician.

On an organisational level, our results shed light on three structural factors that hinder COC. First, ED activities in Brussels are three times more elevated than those in rural areas. In a previous study, actors from both levels of care have identified this workload as a major factor hindering communication and coordination between them. ${ }^{5}$ It has long been recognised that increasing access to general practitioners would decrease use of emergency services $^{27-29}$ and that stronger primary care (in terms of accessibility, comprehensiveness and continuity) would lead to improved population health and lower healthcare service use. ${ }^{30}$ Reinforcing primary care in Belgium is becoming ever more relevant, given the current shifts towards community-based care and early hospital discharge. Furthermore, the ageing population and the increase in comorbid chronic diseases ${ }^{31-34}$ are expected to put further strain on primary care. Given these trends, relevant recommendations include enhancing the recruitment and retention of PCPs, ${ }^{35}{ }^{36}$ developing general practice cooperatives outside normal working hours, ${ }^{37}$ improving availability of diagnostic facilities, ${ }^{36}$ and enhancing coordination within primary care and across levels by providing financial incentives. ${ }^{36}$

Second, the limitations of information sharing systems and communication issues between the two levels of care could explain the high perception of redundant medical investigations reported in our study. Again, this hints at the influence of informational continuity on management continuity, especially with increasing geographical distances. Thus, it is essential to invest in a robust infrastructure to decrease inefficiencies in providing care. ${ }^{37}$

Finally, there is a power struggle between providers due to the fee-for-service payment system in Belgium. A recent study exploring collaborations between ED teams and PCPs in the same Belgian regions as our project showed that in Charleroi (ED 3), competition between hospitals is intense because of proximity. Thus, PCPs hold the economic power as they are the 'patient providers'. Consequently, collaboration suffers; emergency physicians consider PCPs to exert their monopoly through the privileged relationship with patients. ${ }^{5}$ This suggests that patients having more trust and satisfaction with their PCPs than in the ED may be symptomatic of this poor coordination between the two levels of care. Thus, there is a need for rethinking the current payment system (of both levels) that encourages competition and hinders coordination. Many European countries have combined alternative payment plans (pay-for-performance, bundle payments and population-based global payments) or have provided these on top of the traditional fee-for-service and capitation payment systems. ${ }^{38}$

Overall, our study identifies the many factors, both individual and organisational, that shape patients' perception of COC. We already know that three types of COC are inter-related and constitute a whole. ${ }^{39}$ However, it is unknown whether one or many factors have more 
influence than others on a patient's care experience, and there is no easy way of assessing this potential classification. Improving service delivery might not be enough to improve patients' perception of COC if not combined with a patient-centred care approach on a clinical, individual level. Previous studies have highlighted the great importance that patients attach to informed discussion and agreement, ${ }^{40}$ effective and empathetic communication, ${ }^{41}$ and mutual and collaborative partnership, ${ }^{42}$ all of which are related to the three types of COC. Our results suggested that these approaches would particularly benefit the highly educated, younger and chronic patients with complex needs.

\section{Strengths and limitations}

Previous studies have examined informational continuity between EDs and primary care level. However, this is the first study to assess the three types of COC between these service providers. Also, by presenting each item separately, we aimed to highlight the different types of interactions assessed in our study. Indeed, some questions assessed patients' perceptions of their interactions with their PCP and emergency physician, while others assessed perceptions of the interactions between physicians.

Moreover, in this study, experience of continuity in healthcare is viewed from the patient's perspective rather than measuring organisational variables. Another strength relates to the multicentre study design. Our survey included a relatively large number of patients from various contexts in Wallonia and Brussels with different sociodemographic characteristics, which strengthen the generalisability (external validity) of the investigation to these regions.

One limitation though could be related to the fact that Flemish-speaking regions of Belgium were not included. This should be considered when evaluating the generalisability of the results at the national level. Another limitation of our study is related to the selection criteria since we have only included patients who were referred by their PCP. This may have left out important data on patients who presented to ED on their own initiative, their perceptions of COC and the reasons for why they did not consider their PCP as the unique entry point to other healthcare services. Finally, although the CCAENA proved relevant for exploring patients' perceptions of COC between the two levels of care, the psychometric properties of the adapted instrument still need to be assessed.

\section{CONCLUSION}

This study confirms the inter-relation of the three types of COC. Informational discontinuity is related to redundant medical investigations and inefficiencies in providing care. In turn, high levels of relational continuity with the PCP may influence management continuity and patient perceptions of high accessibility to PCPs. In addition, communication and collaboration issues between healthcare providers from both levels of care can influence the relational continuity with PCPs and emergency physicians.

On an individual level, a more enhanced patientcentred approach could be beneficial in improving patient experiences of care, in particular, those who are younger, highly educated and with chronic illness. As for Belgian healthcare services, while patients report high satisfaction and ease of accessibility, efforts need to be directed towards improving system efficiency.

Finally, this study reinforces the need for a stronger primary care level to improve the patient care experience, but also to benefit the healthcare system by reducing overuse of emergency services.

Acknowledgements The authors are most grateful to the hospitals who gave them the approval for data collection in their emergency departments. They would also like to express their gratefulness to the research assistants who collected data in the five hospitals.

Contributors MK and JM contributed to the conception and design of the survey and to the acquisition of data: data collection tool adaptation, approval of hospitals, recruitment of research trainers, and ethics approval. MK and A-SL contributed to the supervision of research trainers and to the data analysis. All authors contributed to data interpretation. MK drafted the manuscript and A-SL and JM revised it critically and gave the final approval of the version to be published.

Funding The authors have not declared a specific grant for this research from any funding agency in the public, commercial or not-for-profit sectors.

Competing interests None declared.

Patient consent for publication Not required.

Ethics approval Ethics committee approval was obtained from the researchers' university: the Hospital and Departmental Ethics Committee, Saint-Luc Catholic University of Louvain, in Brussels, and from each of the collaborating hospitals. All patients gave written informed consent to take part in the survey.

Provenance and peer review Not commissioned; externally peer reviewed.

Data availability statement All data relevant to the study are included in the article or uploaded as supplementary information.

Open access This is an open access article distributed in accordance with the Creative Commons Attribution Non Commercial (CC BY-NC 4.0) license, which permits others to distribute, remix, adapt, build upon this work non-commercially, and license their derivative works on different terms, provided the original work is properly cited, appropriate credit is given, any changes made indicated, and the use is non-commercial. See: http://creativecommons.org/licenses/by-nc/4.0/.

ORCID iD

Marlene Karam http://orcid.org/0000-0001-5277-2000

\section{REFERENCES}

1 Hunchak C, Tannenbaum D, Roberts M, et al. Closing the circle of care: implementation of a web-based communication tool to improve emergency department discharge communication with family physicians. CJEM 2015;17:123-30.

2 Afilalo M, Lang E, Léger R, et al. Impact of a standardized communication system on continuity of care between family physicians and the emergency department. CJEM 2007;9:79-86.

3 Watkins LM, Patrician PA. Handoff communication from the emergency department to primary care. Adv Emerg Nurs $J$ 2014;36:44-51.

4 Dardenne E. Identification of communication issues between emergency physicians and general practitioners in Namur region and possible improvements [Identification des problèmes de communication entre les urgentistes et les généralistes en région namuroise et élaboration de pistes pour l'améliorer] [master's thesis]. Belgium: Catholic University of Louvain, 2015: 62.

5 Karam M, Tricas-Sauras S, Darras E, et al. Interprofessional collaboration between general physicians and emergency 
department teams in Belgium: a qualitative study. Int $\mathrm{J}$ Integr Care 2017; $17: 9$

6 Haggerty JL, Reid RJ, Freeman GK, et al. Continuity of care: a multidisciplinary review. BMJ 2003;327:1219-21.

7 Reid JH, Haggerty J, McKendry R. Defusing the confusion: concepts and measures of continuity of healthcare. 50. Canadian Health Services Research Foundation, 2002.

8 Waibel S, Vargas I, Aller M-B, et al. Continuity of clinical management and information across care levels: perceptions of users of different healthcare areas in the Catalan National health system. BMC Health Serv Res 2016;16:466.

9 Medina-Mirapeix F, Oliveira-Sousa SL, Sobral-Ferreira M, et al. What elements of the informational, management, and relational continuity are associated with patient satisfaction with rehabilitation care and global rating change? Arch Phys Med Rehabil 2013;94:2248-54.

10 Salisbury C, Sampson F, Ridd M, et al. How should continuity of care in primary health care be assessed? Br J Gen Pract 2009;59:e134-41.

11 Aller M-B, Vargas I, Garcia-Subirats I, et al. A tool for assessing continuity of care across care levels: an extended psychometric validation of the CCAENA questionnaire. Int $J$ Integr Care 2013;13:e050.

12 de Villiers MR, de Villiers PJT, Kent AP. The Delphi technique in health sciences education research. Med Teach 2005;27:639-43.

13 Hojat M, Ward J, Spandorfer J, et al. The Jefferson scale of attitudes toward interprofessional collaboration (JeffSATIC): development and multi-institution psychometric data. J Interprof Care 2015;29:238-44.

14 Nutting PA, Goodwin MA, Flocke SA, et al. Continuity of primary care: to whom does it matter and when? Ann Fam Med 2003;1:149-55.

15 Health Quality Ontario. Continuity of care to optimize chronic disease management in the community setting. An evidence-based analysis. Ont Health Technol Assess Ser 2013;13:1-41.

16 Hill KM, Twiddy M, Hewison J, et al. Measuring patient-perceived continuity of care for patients with long-term conditions in primary care. BMC Fam Pract 2014;15:191.

17 Cowie L, Morgan M, White P, et al. Experience of continuity of care of patients with multiple long-term conditions in England. J Health Serv Res Policy 2009;14:82-7.

18 Aller M-B, Vargas I, Waibel S, et al. A comprehensive analysis of patients' perceptions of continuity of care and their associated factors. Int J Qual Health Care 2013;25:291-9.

19 Aller M-B, Vargas I, Waibel S, et al. Factors associated to experienced continuity of care between primary and outpatient secondary care in the Catalan public healthcare system. Gaceta Sanitaria 2013;27:207-13.

20 Bowling A, Rowe G, McKee M. Patients' experiences of their healthcare in relation to their expectations and satisfaction: a population survey. J R Soc Med 2013;106:143-9.

21 Belgian Healthcare Knowledge Center. Organization and payment of emergency care services. Belgium: KCE, 2016. Available: https://kce. fgov.be/sites/default/files/atoms/files/KCE_263_Organisation_and payment_of_emergency_care_services.pdf [Accessed 13 Apr 2018].

22 Missine S, Sarah L. General Physicians in Brussels Region : who are they? Where do they practice and where are the potentiel shortage threats? [Les médecins généralistes en Région bruxelloise : qui sont-ils, où pratiquent-ils et où se situent les potentielles pénuries?] Brussels: Observatory for health and social services, Common Community Commission, 2018: 43. http://www.ccc-ggc.brussels/ sites/default/files/documents/graphics/dossiers/dossier_2018-02 medecins generalistes bruxelles.pdf

23 Agency for a life of quality [Agence pour une vie de qualité : AVIQ]. Walloon Cadastre of General Physicians [Cadastre wallon des médecins généralistes] [internet]. Walloonia: AVIQ, 2016: 16. http:// sante.wallonie.be/sites/default/files/MG-cadastre-2016.pdf

24 Le Breton-Lerouvillois G. Atlas of medical demography in France. [Atlas de la démographie médicale en France] [internet]. France: National council of the order of doctors, 2016: 326. https://www. conseil-national.medecin.fr/node/1476

25 Nuffieldtrust, Evidence for better healthcare. Number of general practitioners per 1,000 population [internet]. UK: Nuffieldtrsut, 2014. https://www.nuffieldtrust.org.uk/chart/number-of-generalpractitioners-per-1-000-population

26 Waibel S, Vargas I, Coderch J, et al. Relational continuity with primary and secondary care doctors: a qualitative study of perceptions of users of the Catalan National health system. BMC Health Serv Res 2018;18:257.

27 Cowling TE, Cecil EV, Soljak MA, et al. Access to primary care and visits to emergency departments in England: a cross-sectional, population-based study. PLoS One 2013;8:e66699.

28 Moineddin R, Meaney C, Agha M, et al. Modeling factors influencing the demand for emergency department services in Ontario: a comparison of methods. BMC Emerg Med 2011;11:13.

29 Basu S, Phillips RS. Reduced emergency department utilization after increased access to primary care. PLoS Med 2016;13:e1002114.

30 Dolton P, Pathania V. Can increased primary care access reduce demand for emergency care? Evidence from England's 7-day GP opening. J Health Econ 2016;49:193-208.

31 Belgian Healthcare Knowledge Center. Performance of the Belgain health system - report 2015. Belgium: KCE, 2016. Available: https:// kce.fgov.be/sites/default/files/atoms/files/KCE_259C_performancer eport2015_0.pdf [Accessed 01 Jul 2018].

32 Belgian Healthcare Knowledge Center. Conceptual framework for the reform of the Belgian Hospital payment system. Belgium: KCE 2014. Available: https://kce.fgov.be/sites/default/files/atoms/files/ KCE_229_Hospital\%20Financing_Report.pdf [Accessed 01 Jul 2018].

33 Organization for Economic Co-operation and Development. Belgium long-term care. Paris: OECD, 2011. Available: http://www.oecd.org/ belgium/47877421.pdf [Accessed 13 Apr 2018].

34 Institut Scientifique de Santé Publique ISP. Enquête de santé belge par interview 2013. [Scientific Institute of Public Health. Health Interview Survey 2013]. Rapport I: Etat de santé et bien-etre. [in French]. Available: https://his.wiv-isp.be/fr/Documents\%20partages/ MA FR 2013.pdf [Accessed 20 Apr 2018].

35 Lorant V, Geerts C, Duchesnes C, et al. Attracting and retaining GPs: a stakeholder survey of priorities. Br J Gen Pract 2011;61:e411-8.

36 Maier M. Strengthening primary health care-but how? Eur J Gen Pract 2014;20:245-6.

37 OECD Publishing. Strengthening primary care systems in Health at a Glance: Europe 2016: State of Health in the EU Cycle [Internet], 2016. Available: http://www.oecd.org/health/health-at-a-glanceeurope-23056088.htm [Accessed 20 Apr 2018].

38 Tsiachristas A. Financial incentives to stimulate integration of care. Int J Integr Care 2016;16:8.

39 Waibel S, Henao D, Aller M-B, et al. What do we know about patients' perceptions of continuity of care? A meta-synthesis of qualitative studies. Int J Qual Health Care 2012;24:39-48.

40 Wolf A, Moore L, Lydahl D, et al. The realities of partnership in person-centred care: a qualitative interview study with patients and professionals. BMJ Open 2017;7:e016491.

41 Little P, Everitt $\mathrm{H}$, Williamson I, et al. Observational study of effect of patient centredness and positive approach on outcomes of general practice consultations. BMJ 2001;323:908-11.

42 Roter $\mathrm{D}$. The enduring and evolving nature of the patient-physician relationship. Patient Educ Couns 2000;39:5-15. 